\title{
Barriers Beyond Words: Cancer, Culture, and Translation in a Community of Russian Speakers
}

\author{
Daniel Dohan, $P h D^{7}$ and Marya Levintova, $P h D^{2}$ \\ ${ }^{1}$ Institute for Health Policy Studies University of California San Francisco, UCSF Box 0936, San Francisco, CA 94143, USA; ${ }^{2}$ Fogarty International \\ Center, National Institutes of Health, Bethesda, MD, USA.
}

\begin{abstract}
BACKGROUND: Language and culture relate in complex ways. Addressing this complexity in the context of language translation is a challenge when caring for patients with limited English proficiency (LEP).
\end{abstract}

OBJECTIVE: To examine processes of care related to language, culture and translation in an LEP population is the objective of this study.

DESIGN: We used community based participatory research to examine the experiences of Russian-speaking cancer patients in San Francisco, California. A Russian Cancer Information Taskforce (RCIT), including community-based organizations, local government, and clinics, participated in all phases of the study.

PARTICIPANTS: A purposeful sample of 74 individuals were the participants of the study.

APPROACH: The RCIT shaped research themes and facilitated access to participants. Methods were focus groups, individual interviews, and participant observation. RCIT reviewed data and provided guidance in interpreting results.

RESULTS: Four themes emerged. (1) Local Russianlanguage resources were seen as inadequate and relatively unavailable compared to other non-English languages; (2) a taboo about the word "cancer" led to language "games" surrounding disclosure; (3) this taboo, and other dynamics of care, reflected expectations that Russian speakers derived from experiences in their countries of origin; (4) using interpreters as cultural brokers or establishing support groups for Russian speakers could help address barriers.

CONCLUSIONS: The language barriers experienced by this LEP population reflect cultural and linguistic issues. Providers should consider partnering with trained interpreters to address the intertwining of language and culture.

KEY WORDS: immigrant health; communication; cancer; qualitative research; vulnerable populations.

J Gen Intern Med 22(Suppl 2):300-5

DOI: $10.1007 / \mathrm{s} 11606-007-0325-y$

(C) Society of General Internal Medicine 2007

\section{INTRODUCTION}

Reflecting the resumption of trans-national migration, the number of U.S. States residents over the age of 5 who speak a language other than English at home exceeded 45 million in the 2000 census. ${ }^{1,2}$ Addressing the health care needs of LEP patients requires attention to both language and culture, which connect in complex ways among diverse patient populations. ${ }^{3-6}$ Research has documented that differences in language and culture can cause breakdowns in provider-patient communication; that communication may be aided by language and cultural concordance between providers and patients; and that when providers and patients do not share a common language, well-trained providers and professional interpretation services provide the best outcomes. ${ }^{7-12}$ Several case studies have documented that poor outcomes can result when the links between language and culture receive insufficient attention, but these linkages have not yet received widespread attention in clinical literature. ${ }^{13-16}$ Key questions for continued exploration include how language and culture together shape the clinical encounter, how the interaction of language and culture is affected by the presence of a trained interpreter, and how health care delivery systems can best meet the challenge of communicating across the linked landscapes of language and culture. ${ }^{17-19}$

The goals of this study were to analyze in a holistic way how language and culture combine to influence communication in everyday clinical encounters and to develop strategies for addressing this issue. To accomplish these goals, we used qualitative research methods to collect data from a purposeful sample of individuals (patients, physicians, nurses, interpreters, and others) involved in cancer care in a Russianspeaking émigré community in San Francisco, California. We focused on cancer care among Russian-speakers because prior research has suggested that linguistic and cultural factors combine to negatively impact processes of cancer care, in general, and among Russian-speaking émigrés in San Francisco, in particular. ${ }^{20-22}$ In addition, because Russianspeakers are generally identified as white, data from this population may shed light on the dynamics of linguistic and cultural barriers per se because barriers experienced by Russian-speakers may not be highly conflated with those stemming from racial minority status. We selected qualitative research methods because these methods are appropriate for documenting processes of care in a holistic way.

\section{METHODS \\ Background and Setting}

Over 2 million people have immigrated to the United States from the countries of the former Soviet Union (FSU, including Russia) since 1954, with main resettlements in California, New 
York, Florida, Texas, New Jersey, and Illinois. ${ }^{23}$ San Francisco is one of the primary resettlement locations for these individuals, with as many as 32,000 monolingual Russian-speaking immigrants according to a 2002 community assessment conducted by the San Francisco Department of Public Health. $^{24}$

Experiences and socialization in the states of the FSU encouraged émigrés to adopt health beliefs and orientations that differ substantially from those that predominate in the United States. In past decades, providers in the U.S. health care system have generally experienced the behavior of FSUorigin patients as demanding and inappropriate. ${ }^{20,25}$ A specific area of difference from U.S. norms is that FSU-origin families often prefer to protect a family member to spare him or her stress or despair, a disclosure practice that can complicate the provider-patient relationship. ${ }^{21}$ Language difficulties present a significant barrier when providing medical care to the émigré community. ${ }^{21}$

\section{Procedures and Participants}

To ensure our work was responsive and meaningful to the community, we adopted precepts of community-based participatory research (CBPR) and grounded theory. ${ }^{26,27}$ The study was initiated and conducted within the framework of the Russian Cancer Information Taskforce (RCIT), which was convened by the local chapter of the American Cancer Society (ACS) to examine and address barriers to cancer care among Russian-speaking émigrés in San Francisco. RCIT included a representative from ACS, providers, and leaders of clinics that provide cancer care to the Russian émigre community, representatives from the local department of public health, and representatives from multiple community-based organizations active in the Russian-speaking community including organizations focused on public health and émigré resettlement. A significant portion of RCIT participants were themselves Russian émigrés whose daily work involved providing care and services to the community. RCIT participated in all aspects of the research including obtaining funding, developing the research strategy and design, developing the interview guides, and reviewing and analyzing data.

We examined issues that arose in providing cancer care to Russian émigrés from multiple perspectives, including those of patients, providers, and families. We used qualitative methods to collect data including focus groups, individual interviews, and participant observation.

We conducted four focus groups-two groups of Russian language interpreters at two medical centers that provide cancer care to the community and two groups of health care providers, including physicians, nurses, social workers, technicians, and counselors, at these centers-following standard methods. ${ }^{28}$ We also conducted individual interviews with Russian-speaking physicians who provide primary care to the community and with Russian-speaking patients and family members. All four focus groups were conducted in English and moderated by the second author; the first author co-moderated three groups and another researcher co-moderated the fourth. The second author is an émigré and fluent Russian speaker who is familiar with the San Francisco community; she conducted the individual interviews, all but one of which were conducted in Russian. To triangulate and confirm data collected via the focus groups and individual interviews, we used fieldnote data collected via well-documented procedures. ${ }^{29}$ With oral consent from all participants, the first author directly observed nearly all aspects of everyday life in clinics in the relevant medical centers. Observations included provider-patient interactions in clinic waiting areas, hallways, and exam rooms and provider-provider interactions in all areas of the clinic. To record observations, the first author made longhand "jottings" in a small notebook and then expanded these jottings into full fieldnotes as soon as possible.

The guides for the focus group and individual interviews were developed in consultation with the RCIT and revised and refined during the course of the project. We used a semistructured format in which moderators and interviewers guided participants to address topics of interest. The interview guides varied according to respondent group, as shown in the Table 1.

Seventy-four subjects participated in this research including 16 RCIT members, 21 focus group participants, 8 individual interviews, and 29 patients, family members, and providers in the participant observation. The use of multiple research methods allowed us to triangulate our results and increase our confidence in their validity. All of our activities were conducted with appropriate human subjects oversight

Table 1. Guiding Questions for Focus Groups and Individual Interviews

\section{Guiding questions}

For all focus groups and interviews

In your view, what are the most substantial issues facing the Russian émigré community with respect to health in general and cancer in particular?

What is working well about the healthcare system in general and cancer care in particular for the Russian-speaking population of San Francisco?

What improvements would you like to see made in how healthcare in general and cancer care in particular is provided to the Russian émigré community of San Francisco?

Do you think written materials, such as pamphlets or newspaper ads, could be useful tools for improving care and/or outreach to this community? How?

If written materials might be useful, what would you like to see included or excluded from those materials to make them as useful as possible?

What kind of training for healthcare providers do you believe would help improve cancer care or outreach to the Russian émigré community?

How can the Russian Cancer Information Taskforce help?

For provider focus groups and interviews only

What are your professional and professional interactions with Russian speakers?

What are some of the challenges that you face in caring for members of this community?

Do you find that Russian émigrés present particular challenges in the provision of cancer care as compared with other patient groups with whom you work?

What resources do you have at hand for providing care to this population?

For patient and family groups and interviews only

What are the most important things for a person to do in order to stay healthy?

What are some of the challenges that Russians in San Francisco face in seeking to stay healthy?

What are some of the challenges that you personally face in seeking to stay healthy?

What are the most important steps that Russians in San Francisco can take to improve their health? 
and approval by relevant institutional review boards (IRB). As a condition of IRB approval, we do not identify the participants or settings of this research.

\section{Analysis}

Data collection and analysis proceeded iteratively and was facilitated by Folio Views computer software. ${ }^{30}$ Our analytical strategy combined aspects of CBPR as well as grounded theory. Following a CBPR approach, we developed a preliminary set of analytical themes via a review of the literature and discussions with the RCIT, and we then used a grounded theory strategy to refine these themes through ongoing analysis during data collection activities. To analyze data, we encouraged RCIT members to review all the data, coded data according to themes of interest, discussed coded content and passages of interest with the RCIT, and identified and discussed new themes and insights that emerged during the data collection process. We wrote analytical memos to summarize, develop, and refine each theme, and these memos became the input for the Results section of this paper. These analytical procedures have been described in the literature. ${ }^{31-33}$

\section{RESULTS}

We identified four themes relevant to the issue of language, culture, and translation: limited resources for Russian speakers; language interpretation and cultural practices related to the disclosure of cancer; Russian émigrés' health care experiences in the FSU as a source of fears, expectations, and "challenging" interactions with providers; and suggestions on how to improve care processes among Russian-speaking émigrés. Each of these themes appeared repeatedly in the data.

\section{Inadequate Russian Language Resources}

The first theme was that local cancer clinics did not provide adequate Russian language resources. Patients and providers felt Russian was underrepresented relative to Spanish and Chinese, and we noticed more Spanish and Chinese signage and printed materials than Russian materials during our clinic observations. Family members and other non-professionals often provided Russian interpretation services, but our informants reported that family members, especially patients' children, often did not have adequate Russian language skills to interpret medical and technical information. In addition, as one interpreter put it,

You cannot ask a family member to bear the burden...in a situation like this, it's very difficult to deliver this kind of news and not have it be either a terrible emotional burden or incredibly edited by the family member to take out the hard parts, to save the person from suffering at that moment.

\section{Culture, Interpretation, and the Disclosure of Cancer}

The "terrible emotional burden" and desire to "take out the hard parts" mentioned by this interpreter related to the cultural taboo against disclosing a cancer diagnosis or even saying the word within the émigré community. Cancer could be seen as a "death sentence" in the émigré community. Telling patients, especially elderly patients, that they have cancer thus could be seen as "taking away their hope and spirit," it could cause them to become depressed, and it could even diminish their willingness or ability to survive. Some providers avoided the "C" word with Russian-speaking patients in the manner this provider described: "I say tumor [and] I think everybody in the room knows what it is and the treatment for a tumor is pretty much the same as treatment for cancer. And we get around it by just kind of using a code word for cancer."

Commonly, however, patients were told of their diagnosis to facilitate full disclosure and informed or shared decisionmaking. Providers noted that in the U.S. medical culture, it is necessary to discuss diagnoses with the patient even if this makes family members angry because "we can't embark on a program of care unless we have the consent and engagement of the person who actually is suffering from the disease." Several providers reported that "the patient would be really open" to full disclosure and "the family seems to be the largest obstacle."

For interpreters, standard disclosure practices could lead to personal and professional dilemmas. One interpreter described an incident that began when a resident "pull[ed] rank on me" and insisted he tell an elderly man he had cancer. The patient replied, "I don't have cancer. No, no, no, this is a mistake." The incident continued:

\begin{abstract}
The son comes by and I'm talking to him and I pull him aside and I said, "do you know that your father has cancer?" And he very matter of factly goes, "Of course I know. He's had it for two years. We've been hiding it from him." I says, "Well, you know, he didn't know." And I'll never forget his face. It just froze and he stared daggers into me. He said, "You told him? You're a Russian man and you told him?" I said, "Well you know, they, you know, I'm just a translator, I'm just translating." He says, "Do you understand what this means to a Russian man? It means you've just given him a death sentence, he is going to lose all hope, he's going to stop eating, he's going to stop drinking, he's just going to curl up in a corner and die. You've just ruined two years of us carefully hiding this from him."
\end{abstract}

Anticipating this kind of dilemma, interpreters often tried to make the disclosure "softer" or to inform physicians "about the culture differences." Some physicians agreed to a softer approach, but some, like the resident above, "ask us to tell word by word."

Interpreters, Russian-speaking providers, and family often characterized the complex interactions related to disclosure as a linguistic and symbolic "game" involving patients, family members, and care providers. Playing the "game" was central to "respecting cultural beliefs". But Russian speakers acknowledged the "game" did not always or necessarily mean patients were unaware of their diagnosis. Even as providers and family took respectful pains to shield patients from this information, patients played their role by feigning ignorance, as one Russian-speaking nurse described.

My father had colon cancer back in Russia, Ukraine, where I'm from, and our family never told him...And what I always felt that he knew what he had and he played the game because he didn't want us to be upset that we know that he knows. I'm absolutely sure.

\section{Translation and Health Care System Expectations}

What accounts for the "game"? Patients, providers, and interpreters and members of the RCIT suggested that differ- 
ences in the health care system of the United States compared to Russia and other states of the former Soviet Union (FSU) helped explain its origin and some other notable features of language use and translation in health care.

Respondents said the "game" of nondisclosure oftentimes reflected the view of cancer as a death sentence. "They're coming from a culture where the treatments that are available here simply did not exist," explained one interpreter. "There's no treatment, there's no cure, there's no hope." Cancer treatment in the United States was seen as far more effective than that in Russia and the FSU, and the view of cancer as death sentence could and did change over time. Respondents reported that as emigrés spent more time in the US, they came to view a cancer diagnosis in different terms and to alter their disclosure preferences. One interpreter with many years of experience in the United States noted that "patients are different now. They've been living here for a while...they look differently at many things." Now, interpreters and providers found they could urge patients to view an early diagnosis as "a glass half full" because successful treatment was still likely. In the context of the U.S. health care system, therefore, respondents generally applauded improved treatments and prospects for recovery.

Other aspects of the U.S. system, particularly the providerpatient relationship, were seen as problematic and sources of difficulty in cancer care. Providers recounted these difficulties in painful detail-Russian-speaking émigrés who violated the norms and rules of the cancer clinic by demanding to be seen without an appointment, by refusing to be seen by some providers (nurses, residents, or fellows) and demanding to be seen by senior physicians, and by engaging in noisy and disruptive emotional displays in clinic waiting rooms and hallways-and we directly observed difficult interactions marked by these kinds of behaviors during clinic observations. Interpreters and Russian-speaking providers associated these difficulties with system differences between the United States and Russia/FSU. The role of the physician was frequently discussed in this context. To be "a real doctor" in the eyes of the émigré community required not just technical skills and training but also having "a heart, soul." Lack of these ineffable qualities revealed themselves in seemingly minor details of how a patient was examined or addressed, as this interpreter focus group discussion highlights.

Respondent 1: Simple things like hands on...Patients get very, almost indignant that they just got palpated for two minutes. I said well they don't know what they're doing, you know, they palpate them and then they send you for a machine.

R2: Or listen through the shirt

$R 1$ (interrupts): - yeah, listening through the stethoscope. In Russia you get palpated for 8,10 minutes -

$R 2$ (continues): - you undress -

$R 1$ (continues): - because you didn't have the machines, but they were experts.

On the other hand, well-intentioned attempts to involve patients could undermine processes of care for patients accustomed to a different medical system. Informed consent, for example, as one Russian-speaking provider explained, "is not only foreign, but I would say makes a lot of the Russian patients skeptical... In Russia, you know, you just say do it and that's it. When you start explaining...the Russians feel that you're somehow equivocating." Translation itself could engen- der skepticism among patients who expect physicians to "listen to the nuances in the person's speech to get a sense of what's wrong with them" because in Russia "they don't have an MRI machine" to turn to.

English-speaking providers recognized that these different expectations of the health care system could lead to breakdowns in provider-patient communication, and at times, spectacular confrontations. One radiation technician described a Russian patient who had "just throw[n] her arms around me, crying, you know, begging me to get the results of her CT scan and the tears streaming down her face." A nurse described Russian-speakers' "strategies" to obtain immediate attention such as "being noisy about it or getting emotional about it or going to the emergency room and saying you have chest pain when you don't." Yet, while recognizing that these interaction styles and strategies reflected differences in their expectations for care processes, providers lamented that they often had the effect of exacerbating communication problems because, as the nurse pointed out, they "actually backfire a lot and make for lots of strained relationships."

\section{Improving Translation and Communication}

Respondents provided two suggestions for improving translation and communication. First, they suggested that physicians and other providers take fuller advantage of professional interpreters' services. Russian speakers believed interpreters could help address cultural differences in disclosure and social differences in treatment expectations if they were trusted to move away from "word by word" translation and to broker relationships between care-providers and patients. Interpreters recognized that providers who see "a thousand to ten thousand cancer patients" had to maintain their "clinical objectivity" for professional and emotional reasons. Interpreters suggested they provide culturally sensitive translation and communication by supporting and encouraging providers to talk to Russian patients "as if it was their own parents." The second suggestion was to establish Russian-language support groups for patients and families. To establish a support group in light of taboos against discussing cancer, respondents suggested selective recruitment and emphasizing prevention. A Russian-speaking physician said, "I know patients for long enough, what is good for them and what is bad for them. So support group is fine for particular population, not for everybody." He continued, "prophylaxis is number one for us. What is important-just get tested. What I'm trying to tell my patients, 'go have a mammogram!" Groups that emphasized prevention, and included survivors, would encourage émigrés to adopt a "glass half full" approach to cancer care, recognize the greater efficacy of cancer treatment in the United States, and overcome diagnosis and disclosure taboos.

\section{DISCUSSION}

Communication between providers and patients who speak different languages requires both linguistic and cultural bridging, and cultural bridging may be particularly challenging in the arena of cancer. The common cultural practice of avoiding the term "cancer" affects cancer care across the spectrum from prevention and screening to treatment and survival with a particular impact on whether cancer patients 
will be willingly informed of their diagnosis by family members. ${ }^{34-40}$ While interpreters can help bridge linguistic gaps between LEP patients and providers, differences in access to care across the spectrum suggest the presence of cultural or other gaps that may undermine communication and access. ${ }^{41-48}$

The results of our study are consistent with past studies of communication and health care-seeking behaviors in Russianspeaking émigré populations. In broad terms, the Russianspeaking population continues to represent a potentially problematic patient population for health care providers in the United States. ${ }^{20,21}$ Some methods for improving communication and access that we suggest here, such as reliance on interpreters as cultural brokers and language translators, also appeared in previous studies. ${ }^{21}$ These continuities in the experiences of Russian speakers in the United States suggest that the cultural practices underlying breakdowns in communication may be relatively stable even as the population of émigrés has changed over time.

Like all case studies, our results have limitations and must be interpreted carefully. Our sample was drawn purposefully rather than to represent any larger population, and our data were collected within a relatively confined setting. It would not be justified to generalize from the results here to the experiences of all Russian-speaking populations nor to other LEP communities. Our use of multiple qualitative methods within the framework of community-based participatory research increased our confidence that our results have validity within the confines of our study sample. Assessing its generalizability would be an appropriate focus for future research.

Despite these limitations, we see this case study as having value in several ways. It exposes the dynamics and logic of how language differences and LEP interact with other social factors to complicate effective communication and care processes within the clinical setting. By examining a European-origin immigrant community, we illustrate how barriers to care for LEP patients may be independent of disadvantage related to minority race. For clinicians, this case study illustrates how language and culture intimately interact in the clinical encounter, highlights some potential drawbacks of communication strategies that rely on word-by-word translation, and offers suggestions of how to partner with trained interpreters to improve communication with LEP patients.

Finally, as a CBPR project, the RCIT has used these findings to seek improvement in cancer care processes in the San Francisco's Russian-speaking community. RCIT developed a new brochure to address cancer treatment in a way the community may find linguistically and culturally appropriate. Future goals of the CBPR include developing a strategy to improve clinical care processes through provider education, changes in clinic procedures, or other innovations.

Acknowledgements: We thank Stuart Henderson for serving as a focus group facilitator and members of the Writing Seminar at the Institute for Health Policy Studies at UCSF for comments on an earlier draft. This research was supported by grants from the San Francisco chapter of the American Cancer Society (no number) and the Mount Zion Health Fund (no number). In addition, Dr. Dohan received support from a Mentored Research Scholar award from the American Cancer Society (\# MRSGT-05-194-01-CPHPS) and Dr. Levintova was supported by a post-doctoral fellowship in health services research from the Agency for Healthcare Research and Quality (\# HHSA 290200600023I).
Conflicts of Interest: None.

Corresponding Author: Daniel Dohan, $\mathrm{PhD}$; Institute for Health Policy Studies University of California San Francisco, 333 California St. Suite 265, UCSF Box 0936, San Francisco, CA 94143, USA (e-mail: Daniel.Dohan@ucsf.edu).

\section{REFERENCES}

1. Massey DS, International Union for the Scientific Study of Population. Committee on South-North Migration. Worlds in Motion: Understanding International Migration at the End of the Millennium. Oxford; New York: Clarendon Press; 2005

2. Shin HB, Bruno R. Language Use and English-speaking Ability: 2000. Washington, D.C.: U.S. Department of commerce census bureau; 2003 October, 2003. Report No.: C2KBR-29.

3. Napoles-Springer A, Perez-Stable EJ. The role of culture and language in determining best practices. J Gen Intern Med 2001;16(7):493-5.

4. In the right words: addressing language and culture in providing health care. Issue brief (Grantmakers Health) 2003(18):1-44.

5. U.S. Department of health and human services office of minority health. National Standards for Culturally and Linguistically Appropriate Services in Health Care: Final Report. Washington, D.C.: U.S. Department of health and human services office of minority health; 2001.

6. Stewart AL, Napoles-Springer A, Perez-Stable EJ. Interpersonal processes of care in diverse populations. Milbank $Q$ 1999;77(3):305-39, 274

7. Baker DW, Hayes R, Fortier JP. Interpreter use and satisfaction with interpersonal aspects of care for Spanish-speaking patients. Med Care 1998;36(10): 1461-70.

8. Baker DW, Parker RM, Williams MV, Coates WC, Pitkin K. Use and effectiveness of interpreters in an emergency department. JAMA 1996;275(10):783-8.

9. Flores G. The impact of medical interpreter services on the quality of health care: a systematic review. Med Care Res Rev 2005;62(3):255-99.

10. Jacobs EA, Lauderdale DS, Meltzer D, Shorey JM, Levinson W, Thisted RA. Impact of interpreter services on delivery of health care to limited-English-proficient patients. J Gen Intern Med 2001;16(7):46874 .

11. Karliner LS, Perez-Stable EJ, Gildengorin G. The language divide. The importance of training in the use of interpreters for outpatient practice. J Gen Intern Med 2004;19(2): 175-83.

12. Wilson E, Chen AH, Grumbach K, Wang F, Fernandez A. Effects of limited English proficiency and physician language on health care comprehension. J Gen Intern Med 2005;20(9):800-6.

13. Anderson LM, Scrimshaw SC, Fullilove MT, Fielding JE, Normand J. Culturally competent healthcare systems. A systematic review. Am J Prev Med 2003;24(3 Suppl):68-79.

14. Browner CH, Preloran HM, Casado MC, Bass HN, Walker AP. Genetic counseling gone awry: miscommunication between prenatal genetic service providers and Mexican-origin clients. Soc Sci Med 2003;56 (9): 1933-46.

15. Elderkin-Thompson V, Silver RC, Waitzkin H. When nurses double as interpreters: a study of Spanish-speaking patients in a US primary care setting. Soc Sci Med 2001;52(9):1343-58.

16. Flores G, Abreu M, Schwartz I, Hill M. The importance of language and culture in pediatric care: case studies from the Latino community. J Pediatr 2000;137(6):842-8.

17. Perez-Stable EJ, Napoles-Springer A. Interpreters and communication in the clinical encounter. Am J Med 2000;108(6):509-10.

18. Paasche-Orlow MK, Schillinger D, Greene SM, Wagner EH. How health care systems can begin to address the challenge of limited literacy. J Gen Intern Med 2006;21(8):884-7.

19. De Alba I, Sweningson JM. English proficiency and physicians recommendation of pap smears among Hispanics. Cancer Detec Prev 2006;30(3):292-6.

20. Brod M, Heurtin-Roberts S. Older Russian emigres and medical care. West J Med 1992;157(3):333-6.

21. Cronkright PJ, DeHaven K, Kraev IA. Issues in the provision of health care to Soviet emigrants. Arch Fam Med 1993;2(4):425-8.

22. Tchen N, Bedard P, Yi GL, Klein M, Cella D, Eremenco S, et al. Quality of life and understanding of disease status among cancer patients of different ethnic origin. Br J Cancer 2003;89(4):641-7. 
23. Schmidley A. U.S. Census Bureau, Current Population Reports, Series P23-206, Profile of the Foreign-born Population in the United States: 2000. Washington, DC: U.S. Government Printing Office; 2001.

24. Erwin P, Chappo L. Russian-speaking Newcomers in San Francisco: A Community Assessment Report. San Francisco, CA: San Francisco Department of Public Health Newcomers Health Program; 2002.

25. Wheat ME, Brownstein H, Kvitash V. Aspects of medical care of Soviet Jewish emigres. West J Med 1983;139(6):900-4.

26. Minkler M, Wallerstein N. Community Based Participatory Research for Health. San Francisco, CA: Jossey-Bass; 2003.

27. Glaser BG, Strauss AL. The Discovery of Grounded Theory: Strategies for Qualitative Research. New York: Aldine Publishing Company; 1967.

28. Morgan DL. Focus Groups as Qualitative Research. Beverly Hills, Calif. Sage Publications; 1988

29. Emerson RM, Fretz RI, Shaw LL. Writing Ethnographic Fieldnotes. Chicago: University of Chicago; 1995.

30. Dohan D, Sanchez-Jankowski M. Using Computers to Analyze Ethnographic Field Data: Theoretical and Practical Considerations. In: Hagan J, editor. Annual Review of Sociology. Palo Alto, CA: Annual Reviews Inc.; 1998. p. 465-86.

31. Bryman A, Burgess RG, eds. Analyzing Qualitative Data. New York: Routledge; 1994

32. Sofaer S. Qualitative methods: what are they and why use them? Health Serv Res 1999;34(5):1101-18.

33. Berg BL. Qualitative Research Methods for the Social Sciences. Boston: Allyn and Bacon; 1995.

34. Gordon DR, Paci E. Disclosure practices and cultural narratives: understanding concealment and silence around cancer in Tuscany, Italy. Soc Sci Med 1997;44(10):1433-52.

35. Gordon DR, Venturini A, Del Turco MR, Palli D, Paci E. What healthy women think, feel and do about cancer, prevention and breast cancer screening in Italy. Eur J Cancer 1991;27(7):913-7.

36. Ell K, Vourlekis B, Muderspach L, Nissly J, Padgett D, Pineda D, et al. Abnormal cervical screen follow-up among low-income Latinas: Project SAFe. J Women's Health Gend-Based Med 2002;11(7): 639-51.
37. Farber JM, Deschamps M, Cameron R. Investigation and Assessment of the Navigator Role in Meeting the Information, Decisional and Educational Needs of Women with Breast Cancer in Canada. Ottowa, Canada: Canadian Breast Cancer Initiative, Centre for Chronic Disease Prevention and Control, Health Canada; 2002.

38. Lannin DR, Mathews HF, Mitchell J, Swanson MS. Impacting cultural attitudes in African-American women to decrease breast cancer mortality. Am J Surg 2002;184(5):418-23.

39. Navarro AM, Senn KL, McNicholas LJ, Kaplan RM, Roppe B, Campo MC. Por La Vida model intervention enhances use of cancer screening tests among Latinas. Am J Prev Med 1998;15(1):32-41.

40. Trans-HHS Cancer Health Disparities Progress Review Group. Making Cancer Health Disparities History. 2004.

41. Jacobs EA, Karavolos K, Rathouz PJ, Ferris TG, Powell LH. Limited English proficiency and breast and cervical cancer screening in a multiethnic population. Am J Public Health 2005;95(8):1410-6.

42. De Alba I, Sweningson JM, Chandy C, Hubbell FA. Impact of English language proficiency on receipt of pap smears among Hispanics. J Gen Intern Med 2004;19(9):967-70.

43. McMullin JM, De Alba I, Chavez LR, Hubbell FA. Influence of beliefs about cervical cancer etiology on Pap smear use among Latina immigrants. Ethn Health 2005;10(1):3-18.

44. Sun A, Wong-Kim E, Stearman S, Chow EA. Quality of life in Chinese patients with breast cancer. Cancer 2005;104(12 Suppl):2952-4.

45. Wong-Kim E, Sun A, Merighi JR, Chow EA. Understanding qualityof-life issues in Chinese women with breast cancer: a qualitative investigation. Cancer Control 2005;12(Suppl 2):6-12.

46. Wong-Kim E, Sun A, DeMattos MC. Assessing cancer beliefs in a Chinese immigrant community. Cancer Control 2003;10(5 Suppl):22-8.

47. Walsh JM, Kaplan CP, Nguyen B, Gildengorin G, McPhee SJ, PerezStable EJ. Barriers to colorectal cancer screening in Latino and Vietnamese Americans. Compared with non-Latino white Americans. J Gen Intern Med 2004;19(2):156-66.

48. Abbe M, Simon C, Angiolillo A, Ruccione K, Kodish ED. A survey of language barriers from the perspective of pediatric oncologists, interpreters, and parents. Pediatr Blood Cancer 2006;47(6):819-24 